\title{
¿Por qué e-learning?
}

\section{Carles Dorado}

A lo largo de la vida de cualquier persona, sus aprendizajes tienen lugar en diferentes «escenarios educativos». Estos escenarios pueden ser más o menos formales, mejor o peor planificados, con o sin soporte institucional y, entre otros muchos factores, con diversos condicionantes físicos, temporales, situacionales y contextuales que, de una u otra manera, conforman esencialmente el aprendizaje en cada etapa vital.

Bajo esta idea, no existe, por tanto, el concepto de escenario educativo perfecto, si no lo es considerando determinados factores que condicionan ese aprendizaje concreto.

Si bien la inclusión y la extensión de las tecnologías de la información y la comunicación, aplicadas a nuestro ámbito educativo, nos ha hecho incorporarlas en los procesos de enseñanza y aprendizaje presenciales y a distancia, esta concepción dicotómica podría inducir a pensar que únicamente existen estas dos posibilidades y que cada una de ellas está llena de virtudes y dificultades. Lo cierto es que la realidad se puede dar de manera mucho más diversa y compleja, lo cual nos permite representarla como un eje bipolar:

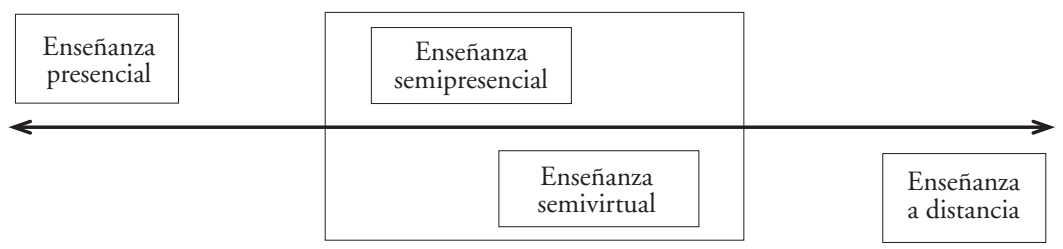

De hecho, los continuos avances tecnológicos y su implantación y uso paulatino en todos los niveles educativos nos hacen pensar en la conveniencia de no identificar estos modelos como puros en lo que respecta a sus estrategias didácticas y a sus formatos metodológicos.

Aún así, y viendo la progresión histórica reciente, se pueden apreciar grandes cambios de mentalidad, y por tanto de posicionamiento, si se extrapolan 
los medios tecnológicos disponibles y utilizados. No es lo mismo trabajar en espacios cerrados, con pizarra, tiza, lápiz y papel, que incluir ordenadores en red y medios audiovisuales y recursos colaborativos de manera habitual en los procesos de enseñanza-aprendizaje.

Es importante comprender que, en cualquiera de estos escenarios educativos, el trabajo con los contenidos y las actividades como vehículos del proceso de enseñanza-aprendizaje se debe estructurar según su tipología en conceptos y redes conceptuales, procedimientos y actitudes y valores, de manera que lo importante, según Casado (2000), es la identificación de «modelos de tecnologías aplicadas a la educación a distancia» que orientan los procesos formativos desde las tendencias transmisivas hasta las colaborativas, pasando por las denominadas interactivas.

Si bien podemos hablar de educación a distancia como del concepto genérico e inclusor dentro de nuestro contexto educativo y sociocultural, a lo largo de los últimos años han ido apareciendo, también, otras terminologías alrededor de esta misma concepción y que presentan peculiaridades específicas. Así, términos como enseñanza abierta, aprendizaje flexible, enseñanza semipresencial, autoformación, educación virtual, teleformación, entre otros, o el mismo e-learning al que nos referimos en esta publicación, han contribuido a ofrecer una visión más concreta de una determinada realidad, con diversos factores determinantes, aunque, en ocasiones, más compleja de entender.

Toda esta mezcla de concepciones y matices se ha visto adobada con diversos factores que inciden en su concepción, los cuales pueden ser, entre otros:

- Idea filosófica o epistemológica que la contenga.

- Concepción política, social y cultural de referencia.

- Necesidades educativas concretas de una zona determinada.

- Perfiles de usuarios a los que va destinada.

- Recursos tecnológicos utilizados.

- Modelos institucionales que la han acogido.

- Plan de marketing que lleva incorporado.

— Influencia de los medios de comunicación.

Todo ello ha generado, en ocasiones, largas discusiones sobre la adecuación y el encaje terminológico y conceptual, debido a las confusiones que determinados usos puedan ocasionar.

De acuerdo con la concepción que propone Marcelo (2003):

e-learning no es un sinónimo de teleformación. Cuando en España se utiliza el concepto teleformación, nos referimos a una formación a distancia (por eso el prefijo tele-) que incorpora el uso de las nuevas tecnologías, especialmente de Internet. Y así se ha planteado la teleformación como un paso más en la educación a distancia. Sin embargo, el concepto e-learning añade un prefijo que, en lugar de ser tele- (distancia), incluye la e de electrónico. Y así, e-learning podría entenderse como la utilización de medios electrónicos con un propósito de aprendizaje. Estos medios electrónicos pueden permitir aprender a distancia 
(teleformación), pero también aprender en un laboratorio mediante simuladores (formación presencial autónoma), así como aprender mediante videoconferencia.

A pesar del anglicismo e-learning y sus connotaciones lingüísticas en las que no entraremos, coincidimos en su implantación como concepto dominante de educación a distancia y en nuestra sociedad actual del conocimiento, si bien también constatamos que, en el ámbito académico, somos más reacios a asumirlo de manera habitual y cotidiana, mientras que nuestra sociedad y nuestro sector empresarial evolucionan más rápidamente en este sentido.

A continuación, nos gustaría presentar sus principales características, a modo de síntesis, siguiendo la propuesta de García Aretio (2003), que recoge estas ideas y las estructura en cuatro dimensiones que incluyen, de alguna manera, las anteriores concepciones y que, a nuestro entender, son realmente importantes:

- Apertura

A diversa y amplia oferta de cursos.

A superación de barreras.

A niveles y estilos de aprendizaje.

A poblaciones numerosas y dispersas.

A la segunda oportunidad.

A las necesidades actuales.

- Flexibilidad

Espacios, ¿dónde estudiar?

Asistencia y tiempo, ¿cuándo estudiar?

Ritmos de aprender, ¿a qué velocidad?

Elección curricular.

Combinación entre familia, trabajo y estudio.

Permanencia en entorno familiar y laboral.

- Eficacia

Sujeto activo de aprendizaje.

Posibilidad de aplicar lo que se aprende.

Integración de medios.

Autoevaluación de los aprendizajes.

Especialistas que elaboran materiales.

- Economía

Al obviar pequeños grupos.

$\mathrm{Al}$ ahorrar gastos de desplazamiento.

Al evitar el abandono del puesto de trabajo o el tiempo extra de formación.

Al permitir la economía de escala. 
Aunque existen diversas perspectivas y enfoques del tema no siempre coincidentes, a modo de conclusión, todos ellos señalan unos mismos elementos comunes que, a modo de resumen, indicamos a continuación:

- Separación entre alumno y profesor (física, temporal, contextual, sociocultural...).

- Utilización de medios tecnológicos diversos que la hacen posible.

- Necesidad del factor humano de apoyo, que supla la presencialidad (tutorías, comunicación directa...).

- Aprendizaje autónomo e independiente.

- Nuevas necesidades, roles, metodologías...

— Racionalización de costos (económicos, personales, temporales...).

También se reconocen, hoy en día, los beneficios relacionados con la utilización de estas tecnologías en los procesos de enseñanza y aprendizaje. Algunos de ellos son:

- Extender el acceso a la educación en términos geográficos.

- Difundir campañas educativas y otra información de valor educativo a grandes audiencias.

- Proporcionar capacitación rápida y eficiente para grupos metaespecíficos.

- Ampliar la capacidad de brindar capacitación en nuevas áreas multidisciplinarias.

- Ofrecer la posibilidad de combinar la educación con el trabajo y la vida familiar.

- Desarrollar múltiples competencias por medio de la educación continua y permanente.

- Destacar la dimensión internacional de la experiencia educativa.

Además, las nuevas consideraciones de planes de estudio y la convergencia europea en planes como Boloña promueven el uso didáctico de herramientas tecnológicas que combinen elementos presenciales, contenidos virtuales, nuevas formas de comunicación y actividades creativas en red, que generen nuevos sistemas de enseñanza y aprendizaje mediado y autónomo a través de la red.

Hemos querido recoger, en estas páginas, una muestra de experiencias y buenas prácticas educativas en la concepción, el diseño y la implementación del e-learning en el entorno universitario y que creemos pueden servir de referencia para el análisis y el estudio de casos adaptados a las nuevas demandas que esta sociedad del conocimiento nos reclama como docentes e investigadores. 